\title{
Study on Rotavirus Infection and Its Genotyping in Children Below 5 Years in South West Iran
}

\author{
Azarakhsh Azaran, Manoochehr Makvandi, ${ }^{1,2}$ Alireza Samarbafzadeh, ${ }^{1,2}$ Niloofar Neisi, ${ }^{1}$ \\ Mohsen Hoseinzadeh, ${ }^{3}$ Mojtaba Rasti, ${ }^{1}$ Majid Teymurirad, ${ }^{4}$ Ali Teimoori, ${ }^{1}$ Mehran Varnaseri, ${ }^{5}$ \\ and Kamyar Makvandi ${ }^{6}$
}

${ }^{1}$ Virology Department, Ahvaz Jundishapur University of Medical Sciences, Ahvaz, IR Iran

${ }_{3}^{2}$ Health Research Institute, Infectious and Tropical Diseases Research Center, Ahvaz Jundishapur University of Medical Sciences, Ahvaz, IR Iran

3 Aboozar Children's Hospital, Ahvaz Jundishapur University of Medical Sciences, Ahvaz, IR Iran

${ }_{5}^{4}$ Virology Department, School of Public Health, Tehran University of Medical Sciences, Tehran, IR Iran

${ }^{5}$ Department of Infectious, Razi Hospital, Ahvaz Jundishapur University of Medical Sciences, Ahvaz, IR Iran

${ }^{6}$ School of Medicine, Ahvaz Jundishapur University of Medical Sciences, Ahvaz, IR Iran

${ }^{*}$ Corresponding author: Manoochehr Makvandi, Health Research Institute, Infectious and Tropical Diseases Research Center, Ahvaz Jundishapur University of Medical Sciences, Ahvaz, IR Iran; Virology Department, Ahvaz Jundishapur University of Medical Sciences, Ahvaz, IR Iran. Tel: +98-6113738313, Fax: +98-6113738313, E-mail: manoochehrmakvandi29@yahoo.com

Received 2015 April 22; Revised 2015 November 11; Accepted 2015 November 23.

\begin{abstract}
Background:Human rotaviruses are the most important agents for severe dehydrating diarrhea in children below 5 years old. Rotaviruses (RV) is a serious public health problem in developing and developed countries.

Objectives: The aim of this study was to determine the prevalence of rotavirus infection and their genotypes in children younger than 5 years of age with acute diarrhea in Ahvaz, Iran.

Materials and Methods: For this study, 200 stool samples from children below 5 years of age with acute diarrhea were collected between October 2011 and March 2012. Initially all stool samples were tested for rotavirus antigen by ELISA, and positive samples were confirmed by RT-PCR targeting the VP6 rotavirus gene. Determination of rotavirus genotypes was carried out by performing RT-PCR for G and P types. Altogether, 15 samples were sequenced.

Results: Out of 200 stool samples, 100 (50\%) had rotavirus antigen detected by ELISA and 73 (36.5\%) were found positive by RT-PCR. Of the rotavirus strains identified, only 63 (86.3\%) were positive for both VP7 and VP4 while 10 (13.7\%) strains were found nontypeable. Rotavirus infection accounts for $36.5 \%$ of gastroenteritis cases in samples from symptomatic children. The most prevalent rotavirus genotypes were G1P $[8](80 \%)$ followed by G2P [4] (20\%).

Conclusions: Our results suggest that group A rotavirus is a major pathogene of acute diarrhea in Ahvaz city. The genotypes circulating are similar with those of other countries.
\end{abstract}

Keywords: Rotavirus, Genotypes, RT-PCR, Sequencing, Diarrhea, Iran

\section{Background}

Human rotavirus is the major agent causing acute diarrhea among children younger than 5 years old (1). Rotavirus infections are frequent with high rates of morbidity in developed countries and mortality in developing countries (2). Rotavirus causes 125 million cases of diarrhea and more than 600,000 children death annually worldwide (3). Rotaviruses are transmitted through direct contact or the fecal-oral route (4). Two RV vaccines, Rotarix ${ }^{\mathrm{TM}}$ (GlaxoSmithKline, Rixensart, Belgium) and Rotateq ${ }^{\mathrm{TM}}$ (Merck and Co. Whitehouse Station, NJ, USA) have been licensed. Both vaccines induce significant protection against rotavirus infection in young children in large-scale clinical trials in developing and developed countries $(5,6)$.

As members of the Reoviridae family, the rotavirus genome consists of 11 segments of double stranded RNA (dsRNA) $(7,8)$, and coding of the 6 structural proteins (VP1-VP7) and 6 nonstructural proteins (NSP1-NSP6) help determine

distinct RV groups A-G. Rotaviruses show great genomic diversity. Group A is a common cause of gastroenteritis among children, while group B rotavirus causes severe diarrhea among adults in China, also rotavirus $\mathrm{B}(\mathrm{RVB})$ is known to be a cause of acute gastroenteritis among children and adults in parts of Asia including China, India, Nepal, Bangladesh and Myanmar (9). Group C rotavirus causes diarrhea in human sporadically in some parts of the world (8).

Rotaviruses are classified into G (VP7) and P (VP4) types, based on genetic diversity of VP7 and VP4 proteins. VP7 and VP4 induce neutralizing antibody responses (7). Group A rotavirus contains 27 different $G$ genotype and 35 different P genotypes (10). The major common rotavirus genotypes G1-G4, G9, P [8], P [4] P [6] are reported around the world (11, 12). G1P [8] is introduced as the dominant genotype worldwide $(13,14)$. In addition, different genotypes such as $\mathrm{G} 5$, G8, and G10 have been reported in several countries (8).

Copyright (C) 2016, Growth \& Development Research Center. This is an open-access article distributed under the terms of the Creative Commons Attribution-NonCommercial 4.0 International License (http://creativecommons.org/licenses/by-nc/4.0/) which permits copy and redistribute the material just in noncommercial usages, provided the original work is properly cited. 
Azaran A et al.

\section{Objectives}

Determination of rotavirus prevalence in individual countries is helpful to establish seasonality, provide guidance for health care workers to treat acute diarrhea, and avoid incorrect use of antibiotics. Due to RV infections specifically in children less than 2 years, WHO monitoring for all countries was proposed in 2005 to identify common genotypes (15). Rotaviruses show great genomic diversity. Genotyping is essential to assess rotavirus epidemiology and the potential for vaccine effectiveness, as well as the impact of vaccine introduction when it occurs (16). Limited information on the molecular characterization of the rotavirus genotype circulating is available in Iran. The objective of this study was to determine the prevalence and its genotyping in Ahvaz city, the capital city of Khuzestan province located at south west Iran with 1.5 million population.

\section{Materials and Methods}

\subsection{Specimen Collection}

After diagnosis of gastroenteritis by a pediatrician, a total of 200 fecal samples were collected from children younger than 5 years old with acute diarrhea (diarrhea, vomiting, abdominal pain less than 2 weeks) referred to Aboozar children's hospital, Ahvaz city, from October 2011 through March 2012. Since the peak season has been noted during October to March in other studies, we chose to enroll patients only between October and March. Aboozar hospital is the only pediatric hospital in Khuzestan province. Demographic data and clinical information such as severity of diarrhea (mucus, watery), vomiting, fever $\geq 38^{\circ} \mathrm{C}$, age, sex, and type of nutrition breast milk, milk formula were also collected from each patient (Table 1). All stool samples were negative for the presence of WBC, parasites, ameba and bacterial culture for salmonella, shigella and other pathogenes. Samples were transported on ice to the virology department, and stored at $-70 \mathrm{C}^{\circ}$ until virologic testing was performed. According to $\mathrm{WHO}$ recommendation children were divided into 9 age groups: 0 - 2, 3 - 5, 6 - 8, 9 - 11, 12 - 17, 18 - 23, 24 - 35, 36 - 47 and 48 - 60 months (17) This study was approved by the ethics committee of Ahvaz Jundishapur University of Medical Sciences.

\subsection{Laboratory Testing}

All stool samples were tested by a commercial ELISA test kit (Generic Assay GmbH, Dahlewitz, Germany) according to the manufacturer's instructions.

\subsection{RNA Extraction and cDNA Synthesis}

Viral RNA was extracted from fecal suspensions using the high pure viral nucleic acid kit (Roche Diagnostics GmbH, Mannheim, Germany) according to the manufacturer's instruction, followed by preparation of cDNA(Fermentas company).

\subsection{RT-PCR for VP6}

Samples positive by ELISA were tested by RT-PCR using specific primers for VP6 to confirm rotavirus. VP6-Forward: GACGGV(c)GCR(b)ACTACATGGT and VP6-Reverse: GTCCAA-TTCATN(d)CCTGGTG [c = (N = A,T,C or G), b = (R $=A$ or $\mathrm{G}), \mathrm{d}=(\mathrm{Y}=\mathrm{C}$ or $\mathrm{T})]$ (18). The reaction mixture containing $2.5 \mu \mathrm{L}$ PCR reaction buffer with $\mathrm{MgCl}_{2} 10 \mathrm{X}$ (Roche, Germany), $0.5 \mu \mathrm{L}$ dNTPs $10 \mathrm{mM}$ (Roche, Germany), $0.2 \mu \mathrm{L}$ of Taq DNA polymerase $5 \mathrm{U}$ (Roche, Germany), $0.25 \mu \mathrm{L}$ of each primer $(100 \mathrm{pmol})$ and $2 \mu \mathrm{L}$ of the template. PCR was performed on Techne Thermocycler (UK) for 35 cycles. Cycling conditions were as follows: $95^{\circ} \mathrm{C}$ for 10 minutes; 35 cycles at $94^{\circ} \mathrm{C}$ for 45 seconds, $50^{\circ} \mathrm{C}$ for 45 seconds, $72^{\circ} \mathrm{C}$ for 45 seconds, and a final elongation at $72^{\circ} \mathrm{C}$ for 10 minutes. The expected PCR product was $382 \mathrm{bp}$. PCR product was subjected to electrophoresis on a $2 \%$ agarose gel, stained with DNA safe stain, and observed under ultraviolet light.

\subsection{RT-PCR for VP7 (Genotyping G)}

The positive samples for Vp6 gene, were tested by RTPCR using common primers for VP7 gene.VP7-Forward: ATGTATGTTATTGAATATACCAC and VP7-Reverse: AACTTGCCACC-ATTTTTTCC (19). The next cycle of PCR was carried out on the same condition with different amount of template $(3 \mu \mathrm{L})$ and number of cycles (30 cycles). Cycling conditions were as follows: $94^{\circ} \mathrm{C}$ for 4 minutes; 30 cycles at $94^{\circ} \mathrm{C}$ for 1 minute, $42^{\circ} \mathrm{C}$ for 1 minute, $72^{\circ} \mathrm{C}$ for 2 minutes; and a final elongation at $72^{\circ} \mathrm{C}$ for 7 minutes. The expected PCR product was $881 \mathrm{bp}$. The PCR product was subjected to electrophoresis on a $1.5 \%$ agarose gel, stained with DNA safe stain, and observed under ultraviolet light.

\subsection{RT-PCR for VP4 (Genotyping P)}

The positive samples for Vp6 gene, were tested by RTPCR using common primers for VP4 gene. Con 3: TGGCTTCGCCATTTTATAGACA and Con 2: ATTTCGGACCAT TTATA-ACC (20). The last cycle of PCR was carried out on the same condition with different amount of template (3 $\mu \mathrm{L}$ ) and number of cycles (30 cycles). Cycling conditions for the VP4 gene PCR were as follows: $94^{\circ} \mathrm{C}$ for 4 minutes; 30 cycles at $94^{\circ} \mathrm{C}$ for 1 minute, $45^{\circ} \mathrm{C}$ for 1 minute, $72^{\circ} \mathrm{C}$ for 2 minutes; and a final elongation at $72^{\circ} \mathrm{C}$ for 7 minutes. The expected PCR product was $876 \mathrm{bp}$. PCR product was subjected to electrophoresis on a 1.5\% agarose gel, stained with DNA safe stain, and observed under ultraviolet light.

\subsection{Nucleotide Sequencing}

The PCR product of 15 samples positive for VP7 and VP4 were sequenced by Bioneer company, South Korea.

\subsection{Ethical Consideration}

This project was approved by health research institute for infectious and tropical diseases research center, Jundishapur University of Medical Sciences. All experiments were performed in compliance with relevant laws and 
institutional guidelines and in accordance with the ethical standards of the declaration of Helsinki. Stool samples were collected only from those patients who were interested to donate their stool voluntarily. The information of each patient under the study was preserved confidentially.

\subsection{Statistical Analysis}

The statistical analysis was performed using SPSS (version 17) software for comparisons of variables using $2 \times$ 2 tables with $\chi^{2}$ test. A P value of $\leq 0.05$ was considered statistically significant.

\section{Results}

Two hundred stool samples collected from 121 boys and 79 girls were collected during October 2011 to March 2012. The patients' age was between 1.5 to 60 months, with a mean age of $17.40 \pm 16.74$ months. Altogether, 100 (50\%) of the 200 stool samples were positive by ELISA. Of these 100 sample 73 (36.5\%) showed positive VP6 by RT-PCR, confirming rotavirus infection. The most positive rotavirus infections with 21 (28.8\%) cases were found among the age group 6 - 8 months and the lowest was $2.7 \%$ among the age group 36 - 47 months $(\mathrm{P}=0.34)$ (Figure 1 ).

Monthly distribution of rotavirus diarrhea among children $<5$ years of age at Aboozar children's hospital, Ahvaz city during October 2011 - March 2012 was as follows: 15.07\% in October, 15.07\% in November, 31.51\% in December, 8.22\% in January, 2.74\% in February and 27.4\% in March. The peak rotavirus infection occurred in December. The highest prevalence of rotavirus was 31.5\% observed in December, and the lowest rate of $2.7 \%$ occurred in February $(\mathrm{P}=0.01)$.

The relation between type of nutrition and rotavirus infection was examined. $37.3 \%$ of patients with non-rotavirus gastroenteritis were breast-fed versus $26.7 \%$ of patients with rotavirus infection $(\mathrm{P}=0.00)$.
The clinical symptoms in 73 patients were as follows: vomiting in 67 (91.8\%), fever in 53 (72.6\%) (Table 1).

$\mathrm{G}$ and $\mathrm{P}$ typing was done for 73 samples. Out of 73 samples, $63(86.3 \%$ ) cases were positive for both VP7 (genotype $\mathrm{G}$ ) and VP4 (genotype P). Ten (13.7\%) samples were nontypeable (4.1\% for G genotype and 9.6\% for P genotype).

The results of sequencing for G-P combinations were as follows: an overall predominance of genotype G1P [8] (80\%) was found during the period of study, with lower incidence of genotype G2P [4] (20\%). GenBank accession numbers for our nucleotide sequences were as follows: KF992572, KF992573, KF992574, KF992575, KF992576, KF992577, KF992578, F992579, KF992580, KF992581, KF992582, KF992583, KF992584, KF992585, KF992586 (Figures 2 and 3).

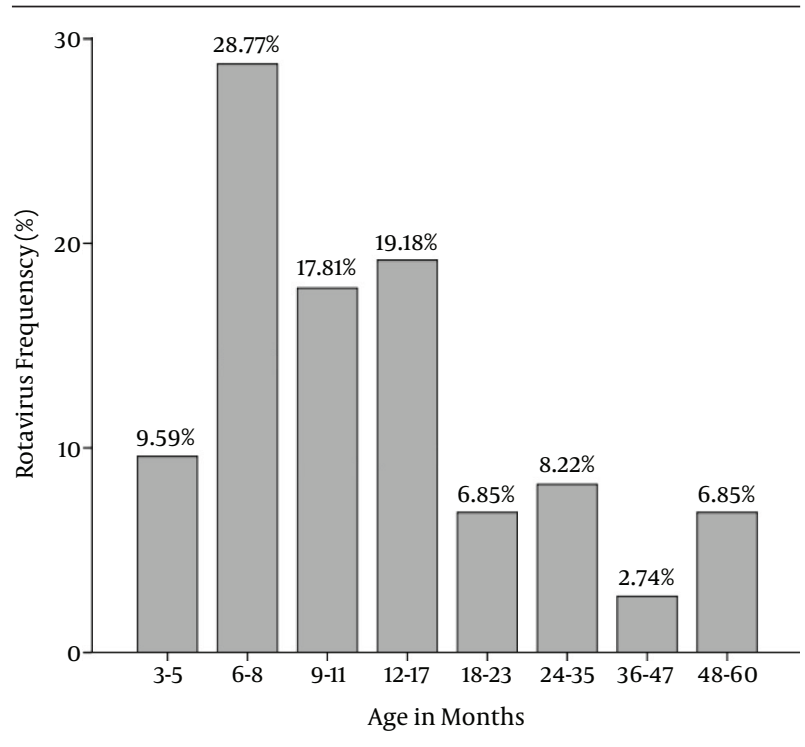

Figure 1. Age Distribution of Rotavirus Isolated From Children With Diarrhea

\begin{tabular}{|c|c|c|c|}
\hline & Rotavirus Infection (Detected in 73 Patients) & Rotavirus Infection (Not Detected in 127 Patients) & PValue $^{b}$ \\
\hline Gender & & & 0.80 \\
\hline Male & 61.6 & 59.8 & \\
\hline Female & 38.4 & 40.2 & \\
\hline Age & & & 0.27 \\
\hline$>2$ years & 17.8 & 19.7 & \\
\hline$<2$ years & 82.2 & 80.3 & \\
\hline Vomiting & 91.8 & 50.4 & $0.00^{\mathrm{C}}$ \\
\hline Fever $\geq 38^{\circ} \mathrm{C}$ & 72.6 & 54.3 & $0.01^{\mathrm{C}}$ \\
\hline Watery stools & 39.7 & 32.3 & 0.15 \\
\hline Type of nutrition & & & $0.00^{\mathrm{C}}$ \\
\hline Breast milk & 26.7 & 37.3 & \\
\hline Milk formula & 40 & 9.8 & \\
\hline Non-milk & 33.33 & 52.9 & \\
\hline
\end{tabular}

\footnotetext{
${ }^{a}$ Data are expressed in \% of subjects infected with rotavirus and patients with non-rotavirus infection.

$\mathrm{b}_{\chi 2}$ test was used to provide the P values.

${ }^{\mathrm{C}}$ Statistically significant difference.
} 
Figure 2. Phylogenetic Tree Based on G Genotype Which Was Drawn Using Mega 5.2 Software

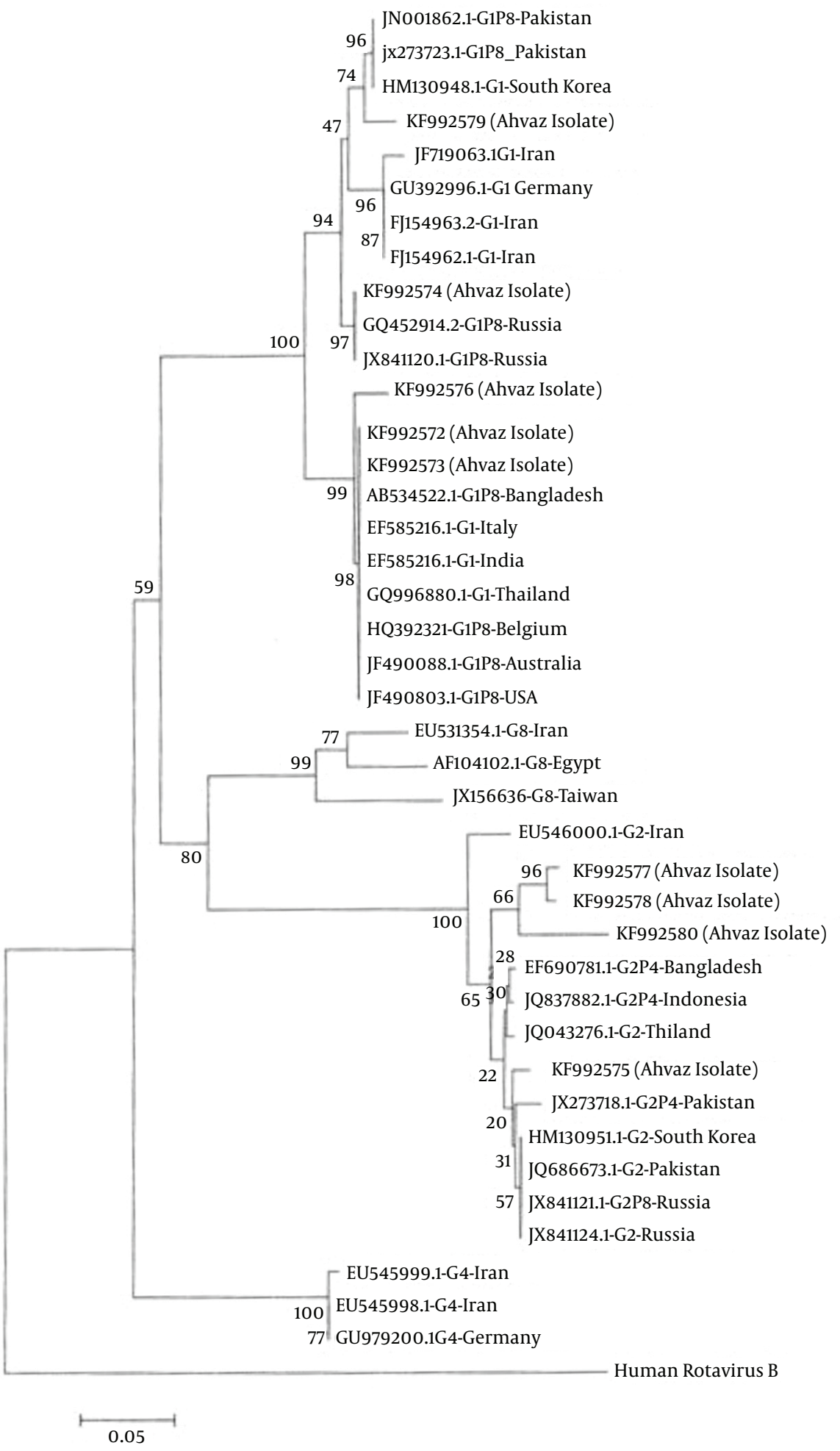

Genebank accession numbers are also given. 
Figure 3. Phylogenetic Tree Based on P Genotype Which Was Drawn Using MEGA 5.2 Software

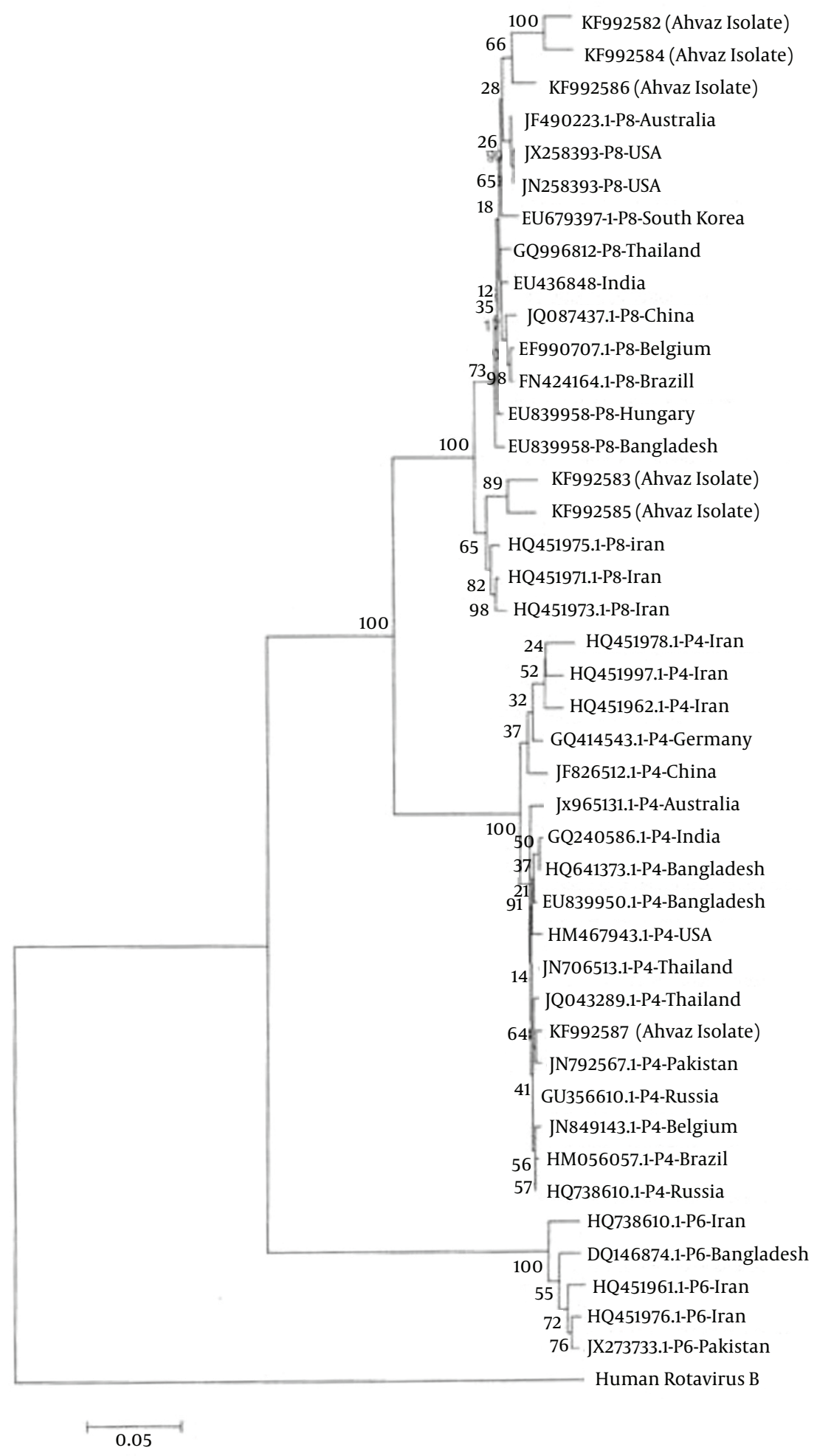

Genebank accession numbers are also given. 


\section{Discussion}

Rotaviruses is the single most important cause of severe diarrhea illness in infants and young children worldwide, accounting for $30 \%$ to $50 \%$ of acute diarrheal illnesses (21). Typing of circulating strains is beginning to occur worldwide as rotavirus vaccines become more widely available and implemented into some countries' standard of care. In our series RV infection was detected in one third (36.5\%) of the children with acute diarrhea. As mentioned in the results section, 27 of the 100 rotavirus ELISA positive specimens were PCR negative. These samples were false positives. Sometimes particles in the stool can cause a false positive test in ELISA method (22). Brandt et al. in cross sectional studies of infants and young children with diarrhea, during a period of 8 years, showed that $34.5 \%$ of children shed rotavirus in feces (23), which is in accord with our results. Reports from other countries have similarly shown that rotaviruses have been present in similar high rates in symptomatic children $<5$ years $(2$, $24)$. Our results are similar to those reported from other countries including India (36.9\%) (25), Denmark (39.9\%) (26) Greece (13), China (24), Bangladesh (27) (40 - 47.4\%), Thailand (43.6\%), Turkey (36.1\%), Pakistan (34\%), Jordan (33\%), Kuwait (40\%) and several cities in Iran including Tehran (35\%), Jahrom (46.2\%), Zanjan (31.5\%) and Isfahan (30.8\%) (28-36), although higher than that figures reported from Venezuela (21.3\%) (2). In addition, according to the WHO-coordinated global Rotavirus surveillance network, global median rotavirus detection among 48 countries was $40 \%$ (37). In our study, most rotavirus cases $60(82.2 \%)$ occurred in children less than 2 years old. In this study, no statistically significant relationship was found between RV infection, and age groups ( $\mathrm{P}=0.34$ ). In addition, since our study was only conducted over one season, we were unable to assess longitudinal changes in genotype expression. Similarly, no relationship was documented between gender and RV infection as it has been reported in other studies $(\mathrm{P}=0.80)(38,39)$.

Seasonality of RV in our study was similar to that of other countries with temperate climate, where RV peak is observed in cold seasons; however in countries with tropical or subtropical climates, the virus circulates year-round (39-41). Breast feeding has appeared to have a protective action against rotavirus infection $(42,43)$. The rate of infection in infants who nourish through breast feeding is low, because maternal antibodies that are the result of previous infections are transmitted with breast milk and protect newborns against serious rotavirus infections $(38,42)$. This study shows that a higher percentage of RV gastroenteritis occurred in children who received milk formula (40\%) compared to those who were fed breast milk (26.7\%). Furthermore, 37.3\% of patients with non-rotavirus gastroenteritis were breast-fed versus $26.7 \%$ of patients with rotavirus infection; Therefore, a statistically significant difference was found between rotavirus diarrhea and type of nutrition $(\mathrm{P}=0.00)$. In this research, children with rotavirus infection had similar rates of vomiting 67 (91.8\%) and fever $53(72.6 \%)$ as in other studies (22). There is statistically a significant difference between rotavirus infection and fever $\geq 38^{\circ} \mathrm{C}(\mathrm{P}=0.01)$, also between RV infection and vomiting $(\mathrm{P}=0.00)$.

Molecular characterization of the rotavirus genotyping circulation has been studied in several cities in Iran (42, 44). One purpose in this study was to determine the VP7 (G genotype) and VP4 (P genotype) of the rotavirus strains. We identified G1 and G2 strains in this study but no G3 and G4 strains were detected. In the present study, the most common rotavirus $\mathrm{G}$ genotype was G1 (55.6\%) followed by G2 strain $44.4 \%$. The rate of P genotype analysis showed that RV strains with P [8] comprised 83.3\% and P [4] 16.7\%. The most prevalent G-P combination of the rotavirus genotyping was G1P [8] (80\%) followed by G2P [4] (20\%). In group A rotavirus G1-G4, G9, P [8], P [4], P [6] with combinations of G1P [8] are dominant around the world (11-14, 22). In Tehran city the most predominant rotaviruses combination genotypes was reported G1P [8] (44). In our study13.7\% of detected RV was nontypeable. Nontypeable RV have been reported by other investigators too. Vizzi et al. has reported 5.7\% nontypeable RV in Valencia, Venezuela (2). Also Kargar et al. has reported $12.5 \%$ nontypeable rotavirus in Jahrom (45). New primer design may be required for recognition of nontypeable genotypes.

To clarify the relationship between the RV isolates, phylogenetic analysis was performed based on VP7 and VP4 regions. RV nucleotide sequences were aligned by Muscle (Mega 5.2 software). The nucleic acid identity among KF992572, KF992573, KF992576 and RV isolates from Bangladesh, Italy, India, Thailand, Belgium, Australia, USA, and Pakistan were 99\%. KF992575, KF992577, KF992578 and KF992580 grouped on one major branch. KF992579 strain has relatively high (99\%) amino acid identities with two isolates from Pakistan and one isolate from South Korea. This tree demonstrated that KF992574 was 99\% identical to Russia isolates (Figure 2).

Figure 3 shows the nucleic acid identity between Ahvaz isolates and other isolates ranging 96 to $99 \%$.

Rotaviruses are responsible for high morbidity and mortality in children below 5 years in developed and developing countries (2). In our study the exact rate of morbidity and mortality is not well documented, so the feature of the applications of the rotavirus vaccine is opaque. The world health organization recommends rotavirus vaccine for all high prevalence regions. It seems according to high prevalence of the disease and its resulted costs and because vaccination is a cost-effective method of prevention of this disease, the use of vaccine is profitable in the vaccination schedules in the developing countries (15). Also the evidence regarding vaccine efficacy, based on the threshold of WHO, implementation of a national rotavirus vaccination program is suggested (46).

The limitations of the study conducted include the lack 
of a full year of surveillance, even though previous studies have provided information on seasonality. In future we would be interested to continue this work on full year of surveillance. Furthermore, the substantial frequency of non-typeable genotypes proves the necessity of using new primer for characterization of unusual genotypes.

We note that this study was limited to the detection of $\mathrm{RV}$, but that other viruses that are important causes of gastrointestinal infection such as enteric adenoviruses (serotypes 40 and 41), noroviruses, sapoviruses, astroviruses, and toroviruses (47) were not studied.

\subsection{Conclusions}

Group A rotavirus is a major pathogene of acute diarrhea in Ahvaz city. In summary, this is the first report of sequencing of rotavirus strains in south Iran. Out of 200 stool samples, $100(50 \%)$ had rotavirus antigen detected by ELISA and 73 (36.5\%) were found positive by RT-PCR. G1P [8] was the predominant type followed by G2P [4] strain in this region. As to high prevalence of rotavirus infection, continuous surveillance is needed to inform diarrhea prevention programs as well as to provide information about the incidence of new rotavirus strains. This will assist policy makers in decision making on rotavirus vaccine introduction.

\section{Acknowledgments}

This paper is issued from thesis of MSc with registration number 90142, and was financially supported by health research institute, infectious and tropical diseases research center, Jundishapur University of Medical Sciences. We acknowledge the editorial assistance of Janet Englund, department of pediatrics, Seattle children's hospital, university of Washington.

\section{References}

1. Parashar UD, Gibson CJ, Bresee JS, Glass RI. Rotavirus and severe childhood diarrhea. Emerg Infect Dis. 2006;12(2):304-6. doi: 10.3201/eid1202.050006. [PubMed:16494759]

2. Vizzi E, Pineros O, Gonzalez GG, Zambrano JL, Ludert JE, Liprandi F. Genotyping of human rotaviruses circulating among children with diarrhea in Valencia, Venezuela. J Med Virol. 2011;83(12):222532. doi: 10.1002/jmv.22211. [PubMed: 22012733]

3. Bass DM. Rotaviruses, caliciviruses, and astroviruses. 19th ed. Philadelphia, Pa: Saunders Elsevier; 2011.

4. Ansari SA, Springthorpe VS, Sattar SA. Survival and vehicular spread of human rotaviruses: possible relation to seasonality of outbreaks. Rev Infect Dis. 1991;13(3):448-61. [PubMed:1866549]

5. Ruiz-Palacios GM, Perez-Schael I, Velazquez FR, Abate $\mathrm{H}$, Breuer T, Clemens SC, et al. Safety and efficacy of an attenuated vaccine against severe rotavirus gastroenteritis. $N$ Engl J Med. 2006;354(1):11-22. doi: 10.1056/NEJMoa052434. [PubMed: 16394298]

6. Vesikari T, Matson DO, Dennehy P, Van Damme P, Santosham M, Rodriguez Z, et al. Safety and efficacy of a pentavalent human-bovine (WC3) reassortant rotavirus vaccine. $N$ Engl J Med. 2006;354(1):23-33. doi: 10.1056/NEJMoa052664. [PubMed: 16394299]

7. Kudesia G, Wreghitt T. Rotavirus in: Clinical and Diagnostic Virology.Newyork: Cambridge University; 2009. doi: 10.1017| CBO9780511575778.

8. Modrow S, Falke D, Truyen U, Schätzl H. Viruses with Double-
Stranded, Segmented RNA Genomes. Molecular Virol.. Berlin: Springer Heidelberg; 2013. pp. 521-53. doi: 10.1007/978-3-64220718-1_17.

9. Alam MM, Pun SB, Gauchan P, Yokoo M, Doan YH, Tran TN, et al. The first identification of rotavirus $B$ from children and adults with acute diarrhoea in kathmandu, Nepal. Trop Med Health. 2013;41(3):129-34. doi: 10.2149/tmh.2013-15. [PubMed:24155654]

10. Matthijnssens J, Ciarlet M, McDonald SM, Attoui H, Banyai K, Brister JR, et al. Uniformity of rotavirus strain nomenclature proposed by the Rotavirus Classification Working Group (RCWG). Arch Virol. 2011;156(8):1397-413. doi: 10.1007/s00705-011-1006-z. [PubMed: 21597953]

11. Gentsch JR, Laird AR, Bielfelt B, Griffin DD, Banyai K, Ramachandran $M$, et al. Serotype diversity and reassortment between human and animal rotavirus strains: implications for rotavirus vaccine programs. J Infect Dis. 2005;192 Suppl 1:S146-59. doi: 10.1086/431499. [PubMed: 16088798]

12. Santos N, Hoshino Y. Global distribution of rotavirus serotypes/genotypes and its implication for the development and implementation of an effective rotavirus vaccine. Rev Med Virol. 2005;15(1):29-56. doi: 10.1002/rmv.448. [PubMed: 15484186]

13. Koukou D, Grivea I, Roma E, Tsioni H, Trimis G, Galanakis E, et al. Frequency, clinical characteristics, and genotype distribution of rotavirus gastroenteritis in Greece (2007-2008). J Med Virol. 2011;83(1):165-9. doi: 10.1002/jmv.21945. [PubMed:21108355]

14. Parashar UD, Bresee JS, Gentsch JR, Glass RI. Rotavirus. Emerg Infect Dis. 1998;4(4):561-70. doi: 10.3201/eid0404.980406. [PubMed: 9866732]

15. Parry J. New vaccines to boost child care in developing countries. Bull World Health Organ. 2007;85(6):426-7. [PubMed: 17639237]

16. Unicomb LE, Kilgore PE, Faruque SG, Hamadani JD, Fuchs GJ, Albert MJ, et al. Anticipating rotavirus vaccines: hospital-based surveillance for rotavirus diarrhea and estimates of disease burden in Bangladesh. Pediatr Infect Dis J. 1997;16(10):947-51. [PubMed: 9380469]

17. WHO . Generic protocols for (i) hospital-based surveillance to estimate the burden of rotavirus gastroenteritis in children and (ii) a community-based survey on utilization of health care services for gastroenteritis in children. Geneva, Switzerland: World Health Organization $\mathrm{CH}$ 1211; 2002. Available from: http:// www.who int/vaccines-documents/. Accessed 2002. Ordering code: $\mathrm{WHO} /$ $\mathrm{V} \& \mathrm{~B} / 02.15$.

18. Iturriza Gomara M, Wong C, Blome S, Desselberger U, Gray J. Molecular characterization of VP6 genes of human rotavirus isolates: correlation of genogroups with subgroups and evidence of independent segregation.J Virol.2002;76(13):6596-601. [PubMed: 12050372]

19. Iturriza-Gomara M, Kang G, Gray J. Rotavirus genotyping: keeping up with an evolving population of human rotaviruses. J Clin Virol. 2004;31(4):259-65. doi:10.1016/j.jcv.2004.04.009. [PubMed: 15494266]

20. Gentsch JR, Glass RI, Woods P, Gouvea V, Gorziglia M, Flores J, et al. Identification of group A rotavirus gene 4 types by polymerase chain reaction. J Clin Microbiol. 1992;30(6):1365-73. [PubMed: 1320625]

21. Bern C, Martines J, de Zoysa I, Glass RI. The magnitude of the global problem of diarrhoeal disease: a ten-year update. Bull World Health Organ. 1992;70(6):705-14. [PubMed:1486666]

22. Greenberg HB, Estes MK. Rotaviruses. In: Knipe DM, Howley PM editors. Fields virology. 6th ed. Philadelphia: Lippincott Williams \& Wilkins, a Welters Kluwer business; 2013. pp. 1347-401.

23. Brandt CD, Kim HW, Rodriguez WJ, Arrobio JO, Jeffries BC, Stallings EP, et al. Pediatric viral gastroenteritis during eight years of study.J Clin Microbiol.1983;18(1):71-8. [PubMed: 6309901]

24. Li DD, Yu QL, Qi SX, Xie Y, Zhang Q, Cui SX, et al. [Study on the epidemiological of rotavirus diarrhea in Lulong in 2008-2009]. Zhonghua Shi Yan He Lin Chuang Bing Du Xue Za Zhi. 2010;24(1):2-4. [PubMed: 20848835]

25. Chakravarti A, Chauhan MS, Sharma A, Verma V. Distribution of human rotavirus $\mathrm{G}$ and $\mathrm{P}$ genotypes in a hospital setting from Northern India. Southeast Asian I Trop Med Public Health. 2010;41(5):1145-52. [PubMed: 21073035]

26. Fischer TK, Rungoe C, Jensen CS, Breindahl M, Jorgensen TR, 
Nielsen JP, et al. The burden of rotavirus disease in Denmark 2009-2010. Pediatr Infect Dis J. 2011;30(7):e126-9. doi: 10.1097| INF.0b013e3182145277. [PubMed: 21386748]

27. Paul SK, Hossain MA, Mahmud MC, Ahmed S, Hossain MA, Nand AK, et al. Instability of human rotavirus $\mathrm{G}$ genotypes circulating in a rural area of Bangladesh. Mymensingh Med J. 2011;20(1):1-8. [PubMed: 21240155]

28. Sungkapalee T, Puntukosit P, Eunsuwan O, Theamboonlers A, Chongsrisawat V, Poovorawan Y. Incidence and clinical manifestations of rotavirus infection among children with acute diarrhea admitted at Buri Ram Hospital, Thailand. Southeast Asian J Trop Med Public Health. 2006;37(6):1125-31. [PubMed: 17333764]

29. Kilic IH, Ozaslan M, Karsligil T, Karagoz ID, Zer Y. Investigation of diarrhea agents less than 5 years of age in summer in Gaziantep/ Turkey. PakJ Biol Sci. 2007;10(17):2915-9. [PubMed:19090199]

30. Alam MM, Khurshid A, Shaukat S, Suleman RM, Sharif S, Angez M, et al. Epidemiology and genetic diversity of rotavirus strains in children with acute gastroenteritis in Lahore, Pakistan. PLoS One 2013;8(6) doi:10.1371/journal.pone.0067998. [PubMed:23825693]

31. Youssef M, Shurman A, Bougnoux M, Rawashdeh M, Bretagne S, Strockbine N. Bacterial, viral and parasitic enteric pathogens associated with acute diarrhea in hospitalized children from northern Jordan. FEMS Immunol Med Microbiol. 2000;28(3):25763. [PubMed:10865179]

32. Sethi SK, Al-Nakib W, Khuffash FA, Majeed HA. Acute diarrhoea and rotavirus infections in young children in Kuwait. Ann Trop Paediatr. 1984;4(2):117-21. [PubMed: 6083746]

33. Kargar M, Zaree B, Tabatabaee H. Genotyping of VP7 protein with Nested RT-PCR in children hospitalized in Tehran [Persian]. J Infect Trop Dis. 2007;12(39):11-7.

34. Kargar M, Akbarizadeh AR, Yaghoubi R. Molecular and serological evaluation of group A rotaviruses isolated from children with diarrhea admitted to Jahrom hospitals with RT PCR technique. [Persian] . Shahrekord J Med Sci. 2010;12(3):15-21.

35. Kazemi A, Zomorosi Soufiani AR, Esmaeelzadeh AR. Comparison of clinical and laboratory findings in acute gastroenteritis caused by rotavirus and other causes among hospitalized children 2 months to 5 years in 2004 [Persian]. Zanjan J Med Sci. 2006;14(57):32-8.

36. Kazemi A, Tabatabaie A, Agha-Ghazvini MR, Kelishadi R. The role of rotavirus in acute pediatric diarrhea in Isfahan, Iran. PakJMed Sci. 2006;22(3):282-5

37. Greenberg HB, Estes MK. Rotaviruses: from pathogenesis to vaccination. Gastroenterology. 2009;136(6):1939-51. doi: 10.1053/j.gastro.2009.02.076. [PubMed:19457420]

38. Samarbafzadeh A, Tehrani EM, Makvandi M, Taremi M. Epidemiological aspects of rotavirus infection in Ahwaz, Iran.J Health Popul Nutr. 2005;23(3):245-9. [PubMed:16262021]

39. Kargar M, Jafarpour T, Najafi A. Epidemiological Survey of Group A Rotaviruses Infection among Children under 5 Years with Acute Diarrhea. Zahedan J Res Med Sci. 2012;14(8):43-7.

40. Rahman M, Sultana R, Ahmed G, Nahar S, Hassan ZM, Saiada F, et al. Prevalence of G2P[4] and G12P[6] rotavirus, Bangladesh. Emerg Infect Dis. 2007;13(1):18-24. doi: 10.3201/eid1301.060910. [PubMed 17370511]

41. Moradi-Lakeh $M$, Shakerian S, Yaghoubi M, Esteghamati A Shokraneh F, Baradaran HR, et al. Rotavirus Infection in Children with Acute Gastroenteritis in Iran: A Systematic Review and Meta-analysis. Int J Prev Med. 2014;5(10):1213-23. [PubMed: 25400878]

42. Modarres S, Modarres S, Oskoii NN. Rotavirus infection in infants and young children with acute gastroenteritis in the Islamic Republic of Iran. East Medit Health J. 1995;1(2):210-4.

43. Santos SM, Ferreira TL, Quintal VS, Carbonare SB, Tino-de-Franco M. Milk from Brazilian women presents secretory IgA antibodies and neutralizes rotavirus G9P[5].JPediatr (RioJ). 2013;89(5):510-3. doi:10.1016/j.jped.2013.02.017. [PubMed:23850115]

44. Farahtaj F, Gallimore CI, Iturriza-Gomara M, Taremi M, Zal MR, Edalatkhah H, et al. Rotavirus VP7, VP4 and VP6 genotypes co-circulating in Tehran, Iran, between 2003 and 2004. Epidemiol Infect. 2007;135(5):834-8. doi: 10.1017/S0950268806007485. [PubMed: 17109772]

45. Kargar M, Zare M, Najafi A. Molecular Epidemiology of Rotavirus Strains Circulating among Children with Gastroenteritis in Iran. Iran J Pediatr. 2012;22(1):63-9. [PubMed: 23056861]

46. Shakerian S, Moradi Lakeh M, Esteghamati A, Zahraei M, Yaghoubi M. Cost-Effectiveness of Rotavirus Vaccination for Under-Five Children in Iran. Iran J Pediatr. 2015;25(4) doi: 10.5812/ijp.2766. [PubMed: 26396704]

47. Storch GA, Wang D. Diagnostic Virology. In: Knipe DM, Howley PM editors. Fields Virology. 6th ed. Philadelphia: Lippincott Williams \& Wilkins, a Welters Kluwer business; 2013. pp. 414-52. 